\title{
NUMERICAL EVALUATION OF THE EFFECT OF COMBINED PENDULUM TUNED MASS DAMPER ON A BASIC VIBRATING SYSTEM
}

\author{
Atef A. Ata ${ }^{1}$, Abanoub G. Kamel ${ }^{2}$ \\ 1,2Alexandria University at Alexandria, Egypt \\ atefa@alexu.edu.eg, abanoub.george@alexu.edu.eg
}

\begin{abstract}
There are many engineering applications utilizing Tuned Mass Damper (TMD), Pendulum Tuned Mass Damper (PTMD) and Combined Pendulum Tuned Mass Damper (CPTMD) in order to alleviate the response of the buildings exposed to catastrophes, strong wind, and earthquake vibrations. The objective of this work is to study the effect of the added Combined Pendulum Tuned Mass Damper (CPTMD) on the vibrating system and to investigate if the added CPTMD will help in damping out the vibrations arises from any excitation source like wind force or from seismic earthquake force. The proposed basic system was modelled mathematically to get the governing Equations of Motion according to Lagrange's equation where the whole system was described by three Degrees of Freedom two translation and one rotation. A parametric study was conducted with different values of constants for the springs and dampers and a simplified model has been derived after making linearization and order of magnitude analysis (OMA). The three Degree of Freedom (DOF) system was put in state-space format before being simulated using (MATLAB ${ }^{\odot}$ ). Output graphs and curves have been obtained and discussed.
\end{abstract}

Keywords: Combined Pendulum, Tuned Mass Damper, Lagrange's Equation, Mathematical Modelling, Simulation, MATLAB ${ }^{\odot} /$ Simulink.

\section{Introduction}

Tuned Mass Dampers (TMDs) are commonly used to attenuate undesirable vibrations in flexible structures and they are very efficient in damping the dynamic response of any construction [9]. Classical TMDs consist of an auxiliary mass, a rigidity component or spring, and viscous damper attached to the vibrating main system to dissipate the mechanical energy as heat. TMD is used as a dynamic vibration absorber, it is one of the efficient and common passive vibration alleviation mechanisms in practice, to deplete the vibration energy [7; 22]. Conventional TMD requires a large bloc and a tremendous space for installation thus creating architectural constraints [14]. Soto and Adeli [6] presented an alternative solution using a Pendulum TMD (PTMD) arrangement comprised of a lump and a cable. When a building exhibits an earthquake movement the PTMD will produce a force in the reverse direction of the floor movement. For example, TAIPEI 101 is located in Taiwan and is consisting of 101 floors and has $508 \mathrm{~m}$ high. With such a huge altitude and high amplitude wind beside earthquake excitations, it was requisite to find out oscillation damping solutions. A heavy PTMD is adopted for damping such vibrations demonstrated [4; 8; 23]. Li [10] and Casciati and Giuliano [3] proposed a Multiple TMDs (MTMDs) and demonstrated that there was a performance improvement using MTMDs as compared to the single TMD (STMD). Nevertheless, the issue of placing huge mass above the structure was still a problem. The modernized solution was to distribute MTMDs along the height of the structures (dMTMDs) [5].

One of the current applications is overhead crane (OHC) or gantry which is modelled as simple PTMD. Gantry crane consists of a cart that passes alongside the path and its translation is in the flat plane [13]. In these systems, the lifted loads from the cart by chain are exposed to swing due to disturbances. After simplification, linearization, and OMA, one can obtain the dynamic model. The main model feature is its ability to match the actual system's nonlinear terms such as (position of the cart and swaying angle) [1]. Qian, et al. [17] Controlled the OHC which is a double-pendulum-type system using Fuzzy Logic.

Zuo, et al. [24], Luo, et al. [11] Investigated Electromagnetic Resonant Shunt Tuned MassDamper-Inerter (ERS-TMDI) scheme that comprises of a supplementary mass, a spiral stiff spring, an inertance bloc, as well as an electromagnetic paralleled RLC. The analysis of frequency-domain reveals that the ERS-TMDI can improve the 
effectiveness of tectonic controller by tuning all the following: the bloc resonances, the electrical resonator, and the inertance, compared to the conventional TMD, where the tuning is done to the mechanical resonance only. Pei, et al. [15; 16] presented two Multi-Resonant Electromagnetic Shunt Damper (MRESD) arrangements, series, as well as parallel, are presented and enhanced.

The performance of the proposed MRESD is compared with analogous MTMDs under the same amount of stiffness ratio. Brzeski, et al. [2] Calculated the complicated bifurcation figures and illustrate how by varying the inerter as well as damper specifications one can remove severe dynamic the schemes' unsteadiness. They also presented the parameters' development of tuned mass absorber TMA to accomplish optimum effectiveness in attenuating the vibrations of the basic body.

On the other hand, Shi, et al. [21] presented a new continual adaptive-passive Eddy Current Tuned Mass Damper (ECTMD) where the damping factor can be varied, which is quite easy to be upgraded to a semi-active one. The outputs reveal that the semiactive ECTMD with adjustable damping has a better influence on vibration control than the optimized passive one. Roffel, et al. [18-20] used point mass planar PTMD which has a spring and damper attached to the pendulum link to enhance the effect caused by the PTMD, but in this study pendulum consist of an inertial mass and a massless link. They attached the PTMD to MDOF main structure directly.

In this study, a pendulum mass attached to a massless link to keep it simple in modelling calculations is attached to a basic vibrating system.
Many cases were conducted with different values of constants for the springs and dampers to determine the most significant impact on damping out the undesired vibrations of the main system caused by an excitation source. A conducted parametric study using different magnitudes of the two masses of CPTMD and varying the massless link length will greatly contribute to reducing both the amplitude and settling time of the basic system.

The paper is organized as follows: Section (2) contains the derivation of the equations of motion using Lagrange's equation as well as the linearization and the transformation to the statespace format. Section (3) contains the numerical simulation and the discussion of the obtained results. Section (4) presents the conclusions followed by references.

\section{Mathematical Modelling}

Consider the main vibrating system consists of mass $\left(\mathrm{m}_{1}\right)$, spring $\left(\mathrm{k}_{1}\right)$ and damper $\left(\mathrm{c}_{1}\right)$ as shown in Figure 1. The system is at rest for $t<0$ and the displacements ( $\mathrm{x}_{1}$ and $\mathrm{x}_{2}$ ) are measured from their respective equilibrium positions before the input force $u(t)$ acts on the system at $t \geq 0$. A CPTMD is attached to the main system which also consists of mass $\left(\mathrm{m}_{2}\right)$, spring $\left(\mathrm{k}_{2}\right)$ and damper $\left(\mathrm{c}_{2}\right)$ with a pendulum of mass $\left(\mathrm{m}_{3}\right)$ is attached to the second mass $\left(\mathrm{m}_{2}\right)$ as shown where the length of massless pendulum link is (L) and makes angle $(\theta)$ with vertical line.

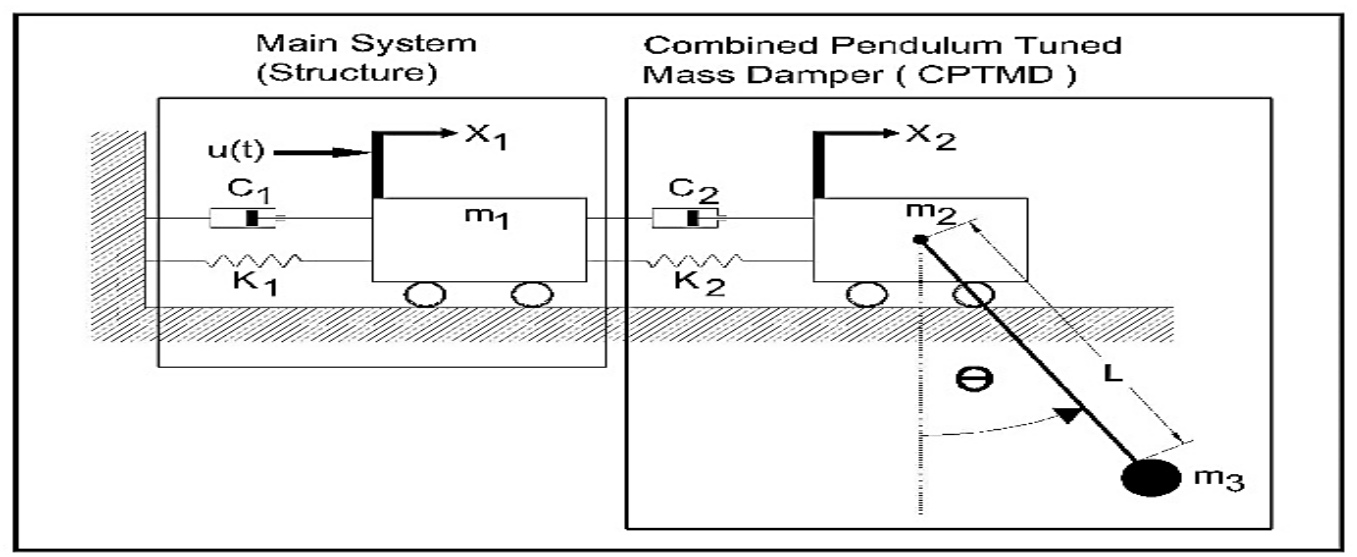

Figure 1: A three DOF system with pendulum attached to the second mass

The equations of motion can be derived using Lagrange's Equation (Mi Han and Benaroya [12]) as follows:

$$
\frac{\mathrm{d}}{\mathrm{dt}}\left(\frac{\partial \mathrm{T}}{\partial \mathrm{q}_{\mathrm{i}}}\right)-\frac{\partial \mathrm{T}}{\partial \mathrm{q}_{\mathrm{i}}}+\frac{\partial \mathrm{R}}{\partial \mathrm{q}_{\mathrm{i}}}+\frac{\partial \mathrm{U}}{\partial \mathrm{q}_{\mathrm{i}}}=\mathrm{Q}_{\mathrm{i}}
$$

where,

q: The generalized coordinates

Q: The generalized forces associated with generalized coordinates
The kinetic energy and the potential energy of the whole system are given by

$$
\begin{aligned}
& \mathrm{T}=\frac{1}{2} \mathrm{~m}_{1} \mathrm{x}_{1}{ }^{2}+\frac{1}{2}\left(\mathrm{~m}_{2}+\mathrm{m}_{2}\right) \mathrm{x}_{2}{ }^{2}+\frac{1}{2} \mathrm{~m}_{3}\left(\mathrm{~L}^{2} \theta^{2}+\right. \\
& \left.2 \mathrm{Lx}_{2} \theta \cos (\theta)\right)
\end{aligned}
$$

$$
\mathrm{U}=\frac{1}{2} \mathrm{k}_{1} \mathrm{x}_{1}^{2}+\frac{1}{2} \mathrm{k}_{2}\left(\mathrm{x}_{1}-\mathrm{x}_{2}\right)^{2}+\mathrm{m}_{\mathrm{a}} \mathrm{gL}(1-\cos (\theta))
$$


While, the dissipative energy is given by

$$
\mathrm{R}=\frac{1}{2} \mathrm{c}_{1} \mathrm{x}_{1}^{2}+\frac{1}{2} \mathrm{c}_{2}\left(\mathrm{x}_{1}-\dot{\mathrm{x}}_{2}\right)^{2}
$$

Equation (1) will be utilized to derive the three generalized coordinates' $\mathrm{x}_{1}, \mathrm{x}_{2}$, and $\theta$ equations. After some algebraic manipulation, the three equations of motion ca ne written as:

$$
\begin{aligned}
& \mathrm{m}_{1} \mathrm{x}_{1}+\mathrm{c}_{1} \mathrm{x}_{1}+\left(\mathrm{k}_{1}+\mathrm{k}_{2}\right) \mathrm{x}_{1}-\mathrm{k}_{2} \mathrm{x}_{2}=\mathrm{u}(\mathrm{t}) \\
& \left(\mathrm{m}_{2}+\mathrm{m}_{2}\right) \mathrm{x}_{2}+c_{2} \dot{\mathrm{x}}_{2}+\mathrm{k}_{2} \mathrm{x}_{2}-c_{2} \dot{\mathrm{x}}_{1}-\mathrm{k}_{2} \mathrm{x}_{1}+ \\
& \mathrm{m}_{\mathrm{a}} \mathrm{L}\left(\theta \cos (\theta)-\theta^{2} \sin (\theta)\right)=0 \\
& \mathrm{~L} \theta+\mathrm{x}_{2} \cos (\theta)+\mathrm{g} \sin (\theta)=0
\end{aligned}
$$

\section{- Linearization of the Equations of Motion}

Before the model linearization, a hypothesis for simple analysis will be assumed; the rotation angle would be kept small and order of magnitude analysis

would be performed which was assumed in Ref. [1] as follows:

$$
\operatorname{Sin}(\theta) \approx \theta, \operatorname{Cos}(\theta) \approx 1, \theta^{2} \approx 0
$$

So that the equations of motion became:

$$
\begin{aligned}
& \mathrm{m}_{1} \overline{\mathrm{x}}_{1}+\mathrm{c}_{1} \dot{\mathrm{x}}_{1}+\left(\mathrm{k}_{1}+\mathrm{k}_{2}\right) \mathrm{x}_{1}-\mathrm{k}_{2} \mathrm{x}_{2}=\mathrm{u}(\mathrm{t}) \\
& \left(\mathrm{m}_{2}+\mathrm{m}_{\mathrm{g}}\right) \mathrm{x}_{2}+\mathrm{c}_{2} \dot{\mathrm{x}}_{2}+\mathrm{k}_{2} \mathrm{x}_{2}-\mathrm{c}_{2} \dot{\mathrm{x}}_{1}-\mathrm{k}_{2} \mathrm{x}_{1}+ \\
& \mathrm{m}_{\mathrm{a}} \mathrm{L} \dot{\theta}=0 \\
& \mathrm{~L} \ddot{\theta}+\overline{\mathrm{x}}_{2}+\mathrm{g} \theta=0
\end{aligned}
$$

After simplification and preparation of equations of motion for state space representation, one can get the final form of them as follows:

$$
\begin{aligned}
& \mathrm{x}_{1}=\frac{1}{\mathrm{~m}_{1}}\left[\mathrm{u}(\mathrm{t})-\mathrm{c}_{1} \dot{\mathrm{x}}_{1}-\left(\mathrm{k}_{1}+\mathrm{k}_{2}\right) \mathrm{x}_{1}+\mathrm{k}_{2} \mathrm{x}_{2}\right] \\
& \mathrm{I}_{2}=\frac{1}{\mathrm{~m}_{2}}\left[\mathrm{c}_{2} \mathrm{x}_{1}+\mathrm{k}_{2} \mathrm{x}_{1}-\mathrm{c}_{2} \dot{\mathrm{x}}_{2}-\mathrm{k}_{2} \mathrm{x}_{2}+\mathrm{m}_{\mathrm{a}} \mathrm{g} \theta\right]
\end{aligned}
$$

$$
\theta=\frac{1}{m_{2} L}\left[c_{2} \mathrm{x}_{2}+k_{2} x_{2}-c_{2} x_{1}^{n}-k_{2} x_{1}-\left(m_{2}+m_{3}\right) g \theta\right]
$$

In State-Space format, the modelling equations; (12),(13) and (14) are represented as:

$$
\begin{aligned}
& \dot{y}(\mathrm{t})=A y(\mathrm{t})+\mathrm{Bu}(\mathrm{t}) \\
& \mathrm{x}(\mathrm{t})=\mathrm{Cy}(\mathrm{t})+\mathrm{Du}(\mathrm{t})
\end{aligned}
$$

Where $\mathrm{y}(\mathrm{t})$ is the state vector describing displacements and velocities of the main system (structure) and CPTMD, $\mathrm{u}(\mathrm{t})$ is the input force to the main system which is the excitation force caused by wind or an earthquake and $x(t)$ is the state vector describing displacements of the main system (structure) and CPTMD (the required output or the system response).

The State Space format can be written in matrix form as:

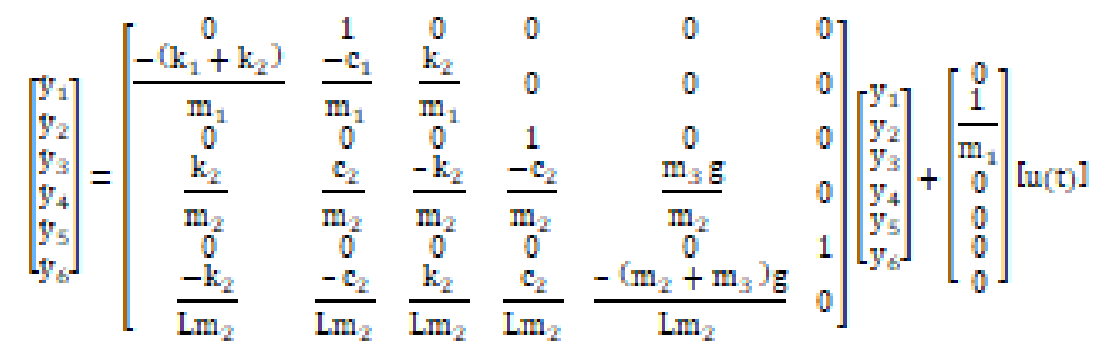

$$
\left[\begin{array}{c}
\mathrm{x}_{1} \\
\mathrm{x}_{2} \\
\theta
\end{array}\right]=\left[\begin{array}{llllll}
1 & 0 & 0 & 0 & 0 & 0 \\
0 & 0 & 1 & 0 & 0 & 0 \\
0 & 0 & 0 & 0 & 1 & 0
\end{array}\right]\left[\begin{array}{l}
y_{1} \\
y_{2} \\
y_{2} \\
y_{4} \\
y_{5} \\
y_{6}
\end{array}\right]
$$

The above (15) and (16) were solved by MATLAB ${ }^{\odot}$ code. While the input force $u(t)$ is represented by a step input.

\section{Numerical Simulation and Discussion}

First of all, a study is conducted on the main existing system (structure) under the excitation force $u(t)$ before attaching the proposed solution which is CPTMD as shown in Figure (2).

Particularly, to see the behavior and to measure its original response. Then CPTMD is attached to the system to enhance its capability against vibrations Figure (3). 
In order to evaluate the structure response; and for the worst case, the value of the damping factor $c_{1}$ is set to zero which means there is no viscous damping. This assumption is valid in the case of rigid structures. Then its damping effects will be studied later on.

Also, two factors will remain constant during the study, the structure mass $m_{1}$ which cannot be changed in the real world (after the structure has been constructed) and the input force $u(t)$.

The reason for that is to study the effect of each component of the system on reducing the amplitude of the vibrating structure.

This could be done by changing one parameter of the system at a time while the others remain constant.

The numerical values for the particular parameters used in the study are shown in Table 1.

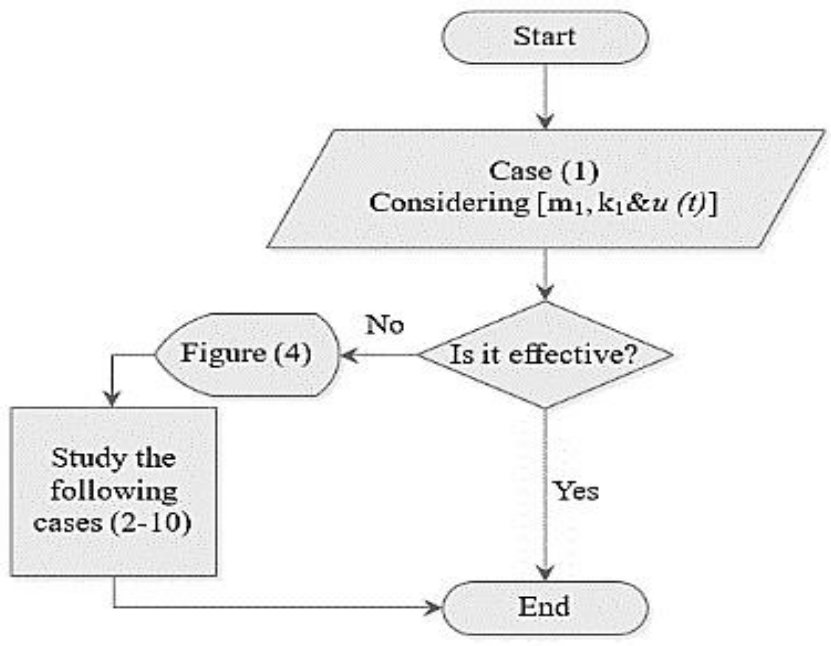

Figure 2: System flow chart without CPTMD

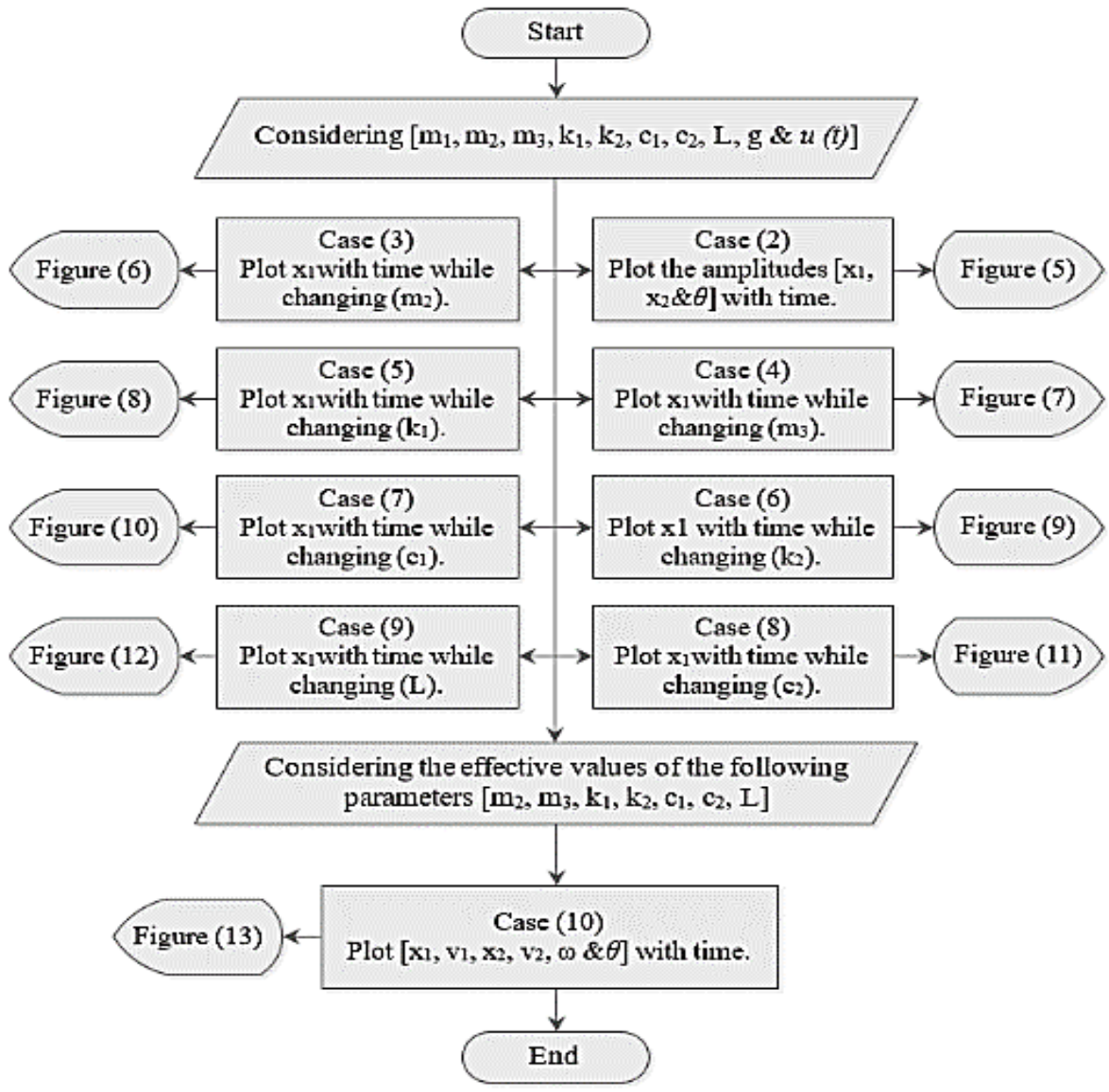

Figure 3: System flow chart with CPTMD 
Table 1. Simulation Parameters

\begin{tabular}{|c|c|c|c|c|c|c|c|c|c|}
\hline Case No. & $\begin{array}{c}\mathbf{m}_{1} \\
(\mathrm{~kg})\end{array}$ & $\begin{array}{c}\mathbf{m}_{2} \\
(\mathbf{k g})\end{array}$ & $\begin{array}{c}\mathbf{m}_{3} \\
(\mathrm{~kg})\end{array}$ & $\begin{array}{c}k_{1} \\
(N / m)\end{array}$ & $\begin{array}{c}k_{2} \\
(N / m)\end{array}$ & $\begin{array}{c}c_{1} \\
(\mathrm{~N} . \mathrm{s} / \mathrm{m})\end{array}$ & $\begin{array}{c}c_{2} \\
\text { (N.s/m) }\end{array}$ & $\begin{array}{c}\mathrm{L} \\
(\mathrm{m})\end{array}$ & $\begin{array}{l}u(t) \\
(N)\end{array}$ \\
\hline Case (1) & 100 & 0 & 0 & 10 & 0 & 0 & 0 & 0 & 10 \\
\hline Case (2) & 100 & 20 & 10 & 50 & 100 & 0 & 100 & 1 & 10 \\
\hline \multirow[b]{2}{*}{ Case (3) } & \multirow[b]{2}{*}{100} & 10 & \multirow[b]{2}{*}{10} & \multirow[b]{2}{*}{50} & \multirow{2}{*}{100} & \multirow[b]{2}{*}{0} & \multirow[b]{2}{*}{100} & \multirow[b]{2}{*}{1} & \multirow{2}{*}{10} \\
\hline & & 50 & & & & & & & \\
\hline \multirow{2}{*}{ Case (4) } & \multirow{2}{*}{100} & \multirow{2}{*}{20} & 10 & \multirow{2}{*}{50} & \multirow{2}{*}{100} & \multirow{2}{*}{0} & \multirow{2}{*}{100} & \multirow{2}{*}{1} & \multirow{2}{*}{10} \\
\hline & & & 50 & & & & & & \\
\hline \multirow{2}{*}{ Case (5) } & \multirow{2}{*}{100} & \multirow{2}{*}{20} & \multirow{2}{*}{10} & 10 & \multirow{2}{*}{100} & \multirow{2}{*}{0} & \multirow{2}{*}{100} & \multirow{2}{*}{1} & \multirow{2}{*}{10} \\
\hline & & & & 50 & & & & & \\
\hline \multirow{2}{*}{ Case (6) } & \multirow{2}{*}{100} & \multirow[b]{2}{*}{20} & \multirow[b]{2}{*}{10} & \multirow[b]{2}{*}{50} & 10 & \multirow{2}{*}{0} & \multirow{2}{*}{100} & \multirow{2}{*}{1} & \\
\hline & & & & & 50 & & & & 10 \\
\hline Case (7) & 100 & 20 & 10 & 50 & 100 & 10 & 100 & 1 & 10 \\
\hline Case $(1)$ & & & & & & 50 & & & \\
\hline Case (8) & 100 & 20 & 10 & 50 & 100 & 0 & 10 & 1 & 10 \\
\hline Case (8) & 100 & 20 & 10 & 50 & 100 & 0 & 50 & 1 & 10 \\
\hline Case (9) & 100 & 20 & 10 & 50 & 100 & 0 & 100 & 1 & 10 \\
\hline & & & & & & 0 & 100 & 5 & 10 \\
\hline Case (10) & 100 & 50 & 50 & 10 & 50 & 10 & 100 & 1 & 10 \\
\hline
\end{tabular}

The performance of the basic system which consists of mass $\mathrm{m}_{1}$ and spring $\mathrm{k}_{1}$ is simulated as shown in Figure (4). It is observed that the system is marginally stable and has a high amplitude of $(2 \mathrm{~m})$. After that, CPTMD was attached to the system and that results in reducing both, amplitude and settling time can be observed clearly in Figure (5). The behavior of $m_{2}$ was very similar to that of $m_{1}$. However, the amplitude of angle $\theta$ was almost zero and diminished with time. Which agreed with the assumptions made in equation (8). The higher $\mathrm{m}_{2}$ and $m_{3}$, the lower the structure amplitude and settling time Figures ( 6 and7).

It can be observed from Figures $(9,10$, and 11) that not only the masses $\mathrm{m}_{2}$ and $\mathrm{m}_{3}$ affect the system performance, but also $\mathrm{k}_{2}$ and $\mathrm{c}_{2}$ contribute to decreasing both amplitude and settling time. On the other hand, the first peak amplitude was greatly dropped by raising the value of the main-spring $\mathrm{k}_{1}$
Figure (8). Upon increasing the main damper coefficient $\mathrm{c}_{1}$ settling time get shortened Figure (10).

On the other hand, changing the pendulum link length L has roughly no effect on the system Figure (12). Eventually, and after using some effective values of the components of the system, its response including linear and rotational displacements and velocities was plotted against time Figure (13).

It is demonstrated that the peak and settling time of the system were reduced considerably in comparison with the basic structure performance Figure (4).

The following Table 2. reveals the change in overshoot percentage and settling time in seconds and percentage reduction in both of them while increasing the illustrated parameters $m_{2}, m_{3}, k_{1}, k_{2}$, C1, C2, L.

\begin{tabular}{|c|c|c|c|c|c|c|}
\hline & & & & & \multicolumn{2}{|c|}{ Table 2. Performance output } \\
\hline $\begin{array}{l}\text { The } \\
\text { variable }\end{array}$ & $\begin{array}{c}\text { First } \\
\text { overshoot } \\
(\%)\end{array}$ & $\begin{array}{c}\text { Second } \\
\text { overshoot } \\
(\%)\end{array}$ & $\begin{array}{c}\text { First } \\
\text { settling } \\
\text { time } \\
\text { (sec) }\end{array}$ & $\begin{array}{c}\text { Second } \\
\text { settling } \\
\text { time } \\
\text { (sec) }\end{array}$ & $\begin{array}{c}\text { Reduction in } \\
\text { overshoot } \\
(\%)\end{array}$ & $\begin{array}{c}\text { Reduction in } \\
\text { settling time } \\
(\%)\end{array}$ \\
\hline $\mathbf{m}_{2}$ & 88.94 & 71.40 & 124.6 & 57.16 & 17.54 & 54.13 \\
\hline $\mathbf{m}_{3}$ & 83.72 & 67.05 & 89.58 & 54.05 & 16.67 & 39.66 \\
\hline $\mathbf{k}_{1}$ & 91.20 & 83.72 & 440.4 & 89.58 & 7.48 & 79.66 \\
\hline $\mathbf{k}_{2}$ & 94.42 & 84.13 & 253.3 & 66.46 & 10.29 & 73.76 \\
\hline $\mathbf{c}_{1}$ & 68.28 & 29.11 & 46.07 & 17.38 & 39.17 & 62.27 \\
\hline $\mathbf{c}_{2}$ & 95.82 & 87.11 & 746.5 & 153.6 & 8.71 & 79.42 \\
\hline $\mathbf{L}$ & 83.72 & 79.30 & 89.58 & 85.76 & 4.42 & 4.26 \\
\hline
\end{tabular}




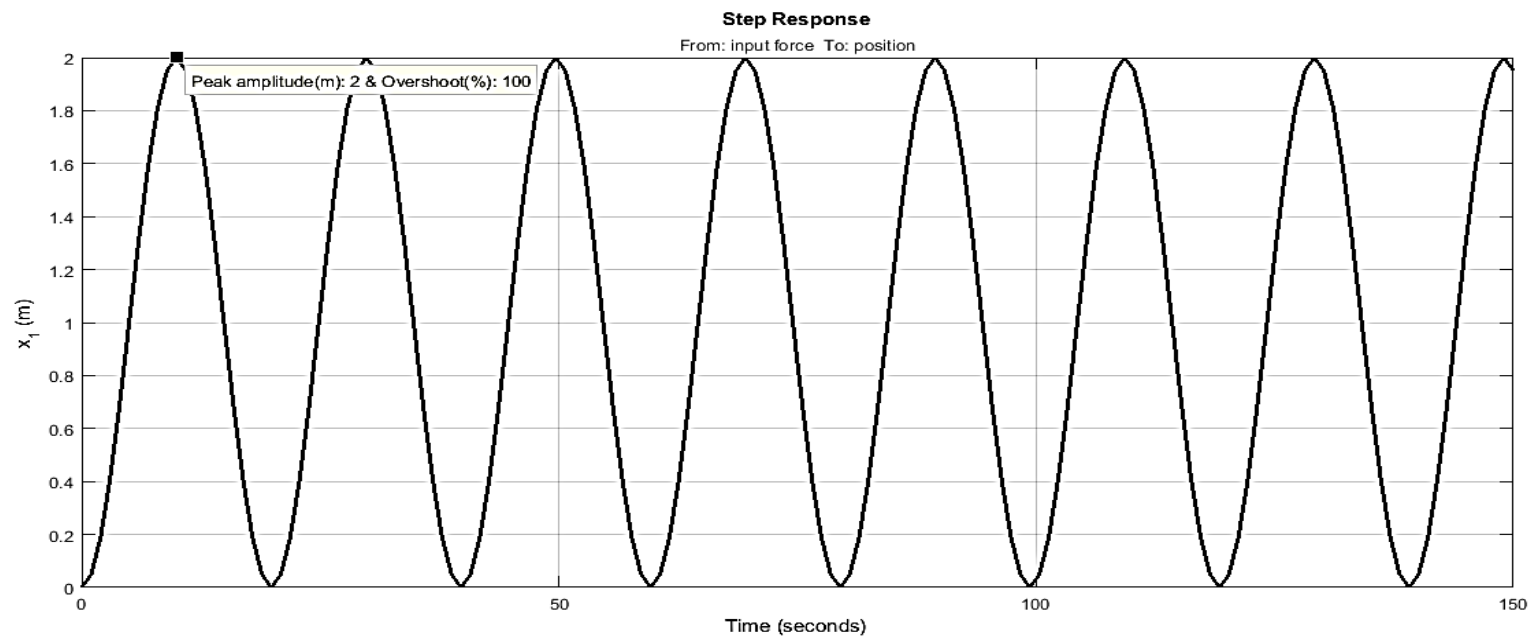

Figure 4: Structure response without CPTMD
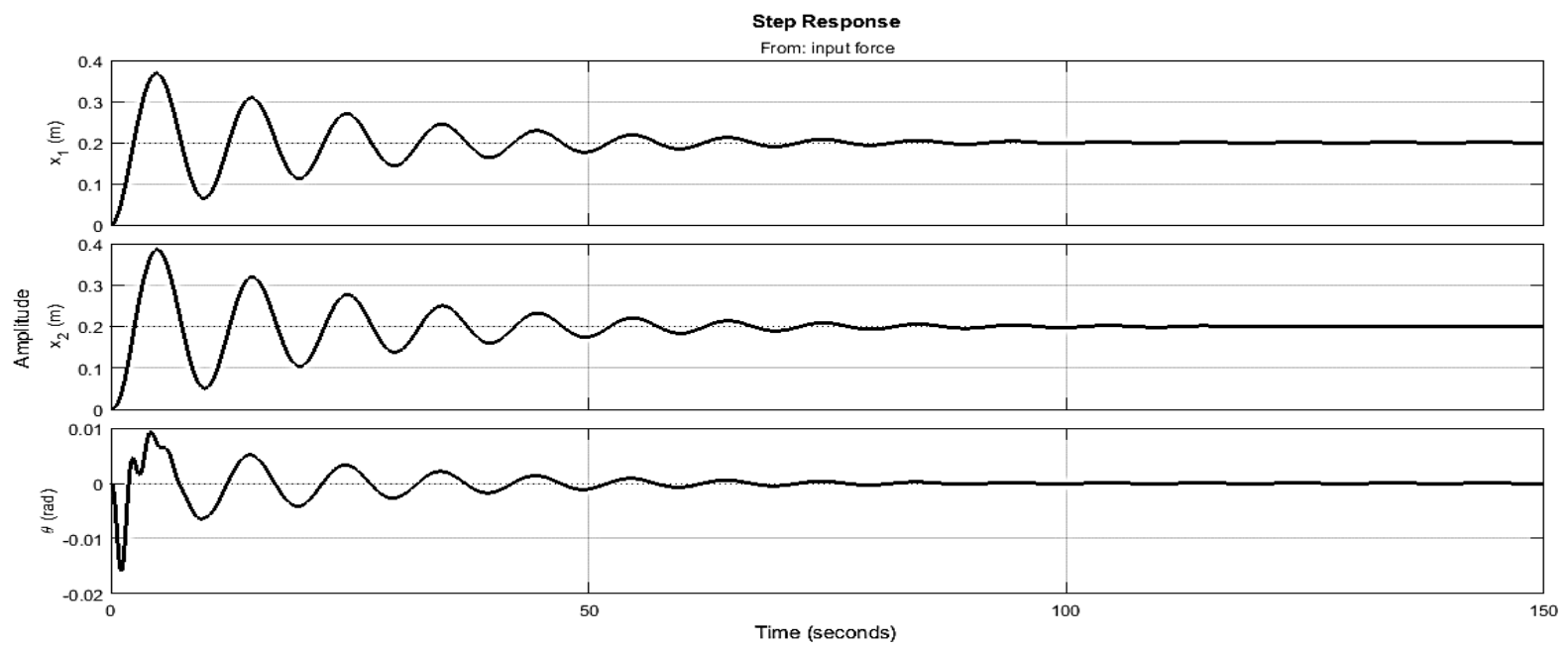

Figure 5: Displacement $\left(x_{1}, x_{2}\right.$ and $\left.\boldsymbol{\theta}\right)$ with time

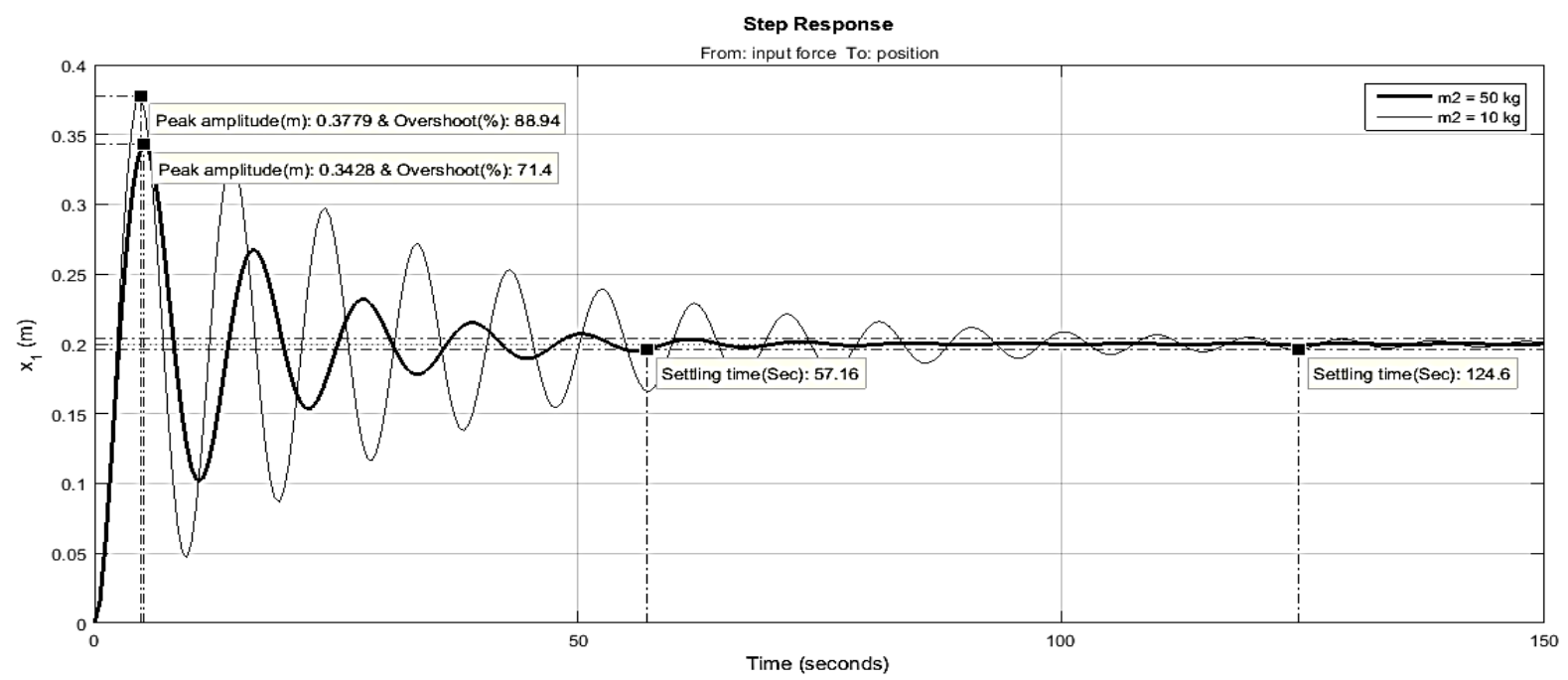

Figure 6: Effect of changing $\left(m_{2}\right)$ on the system 


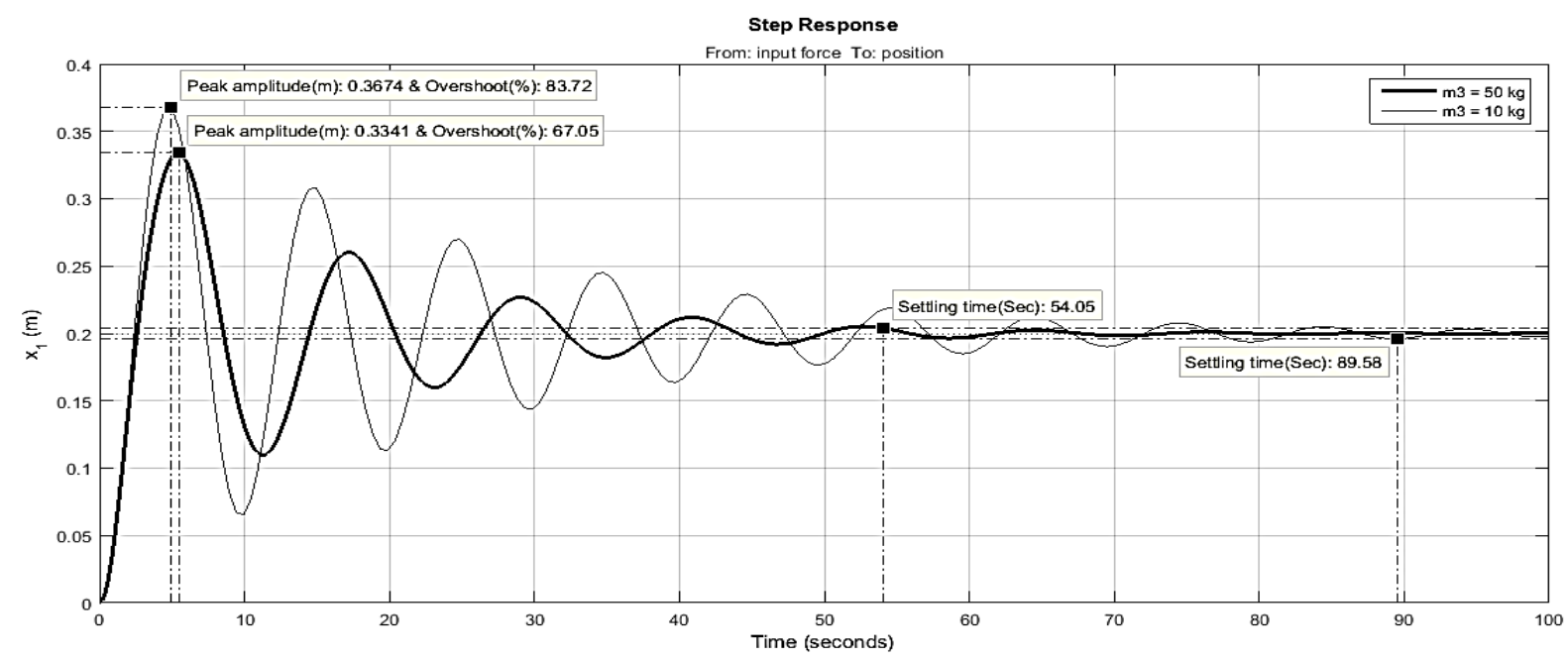

Figure 7: Effect of changing $\left(\mathrm{m}_{3}\right)$ on the system

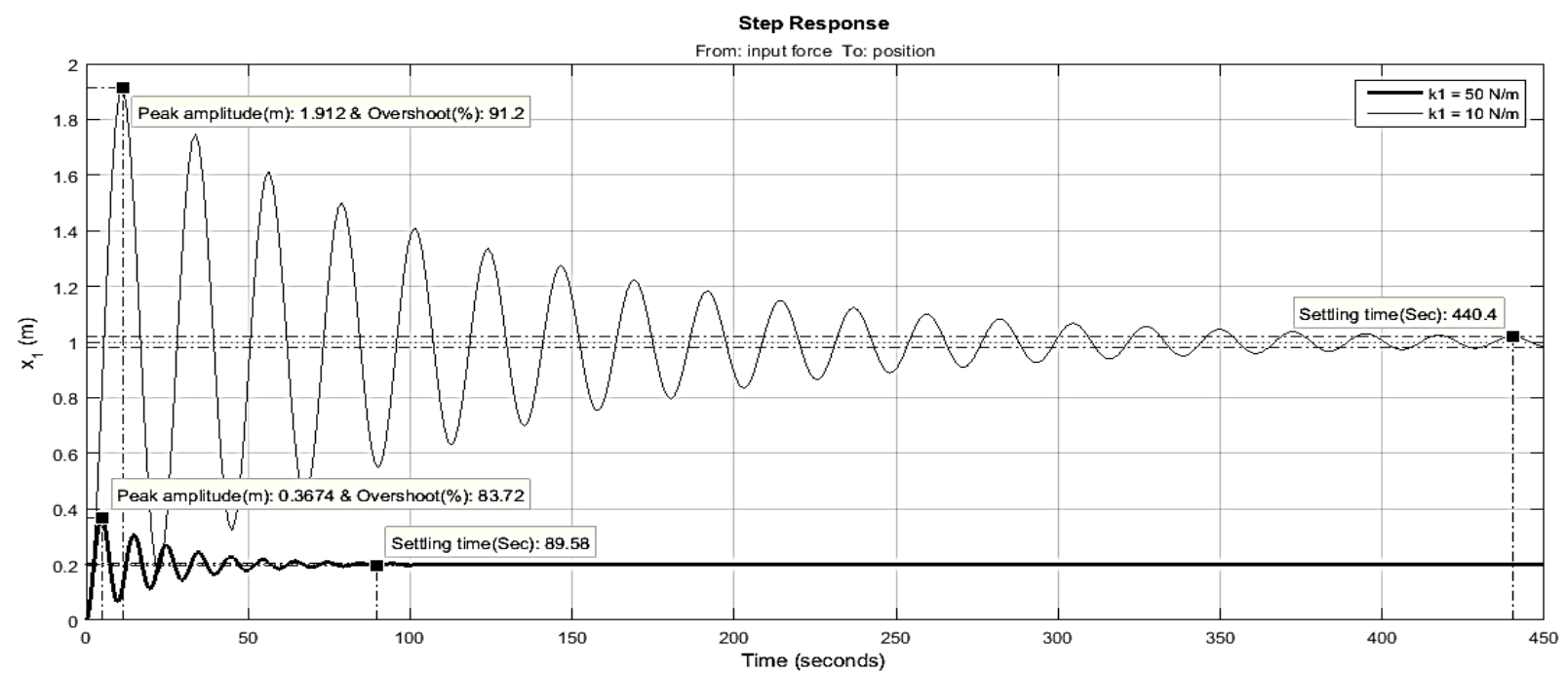

Figure 8: Effect of changing ( $\left.\mathrm{k}_{1}\right)$ on the system

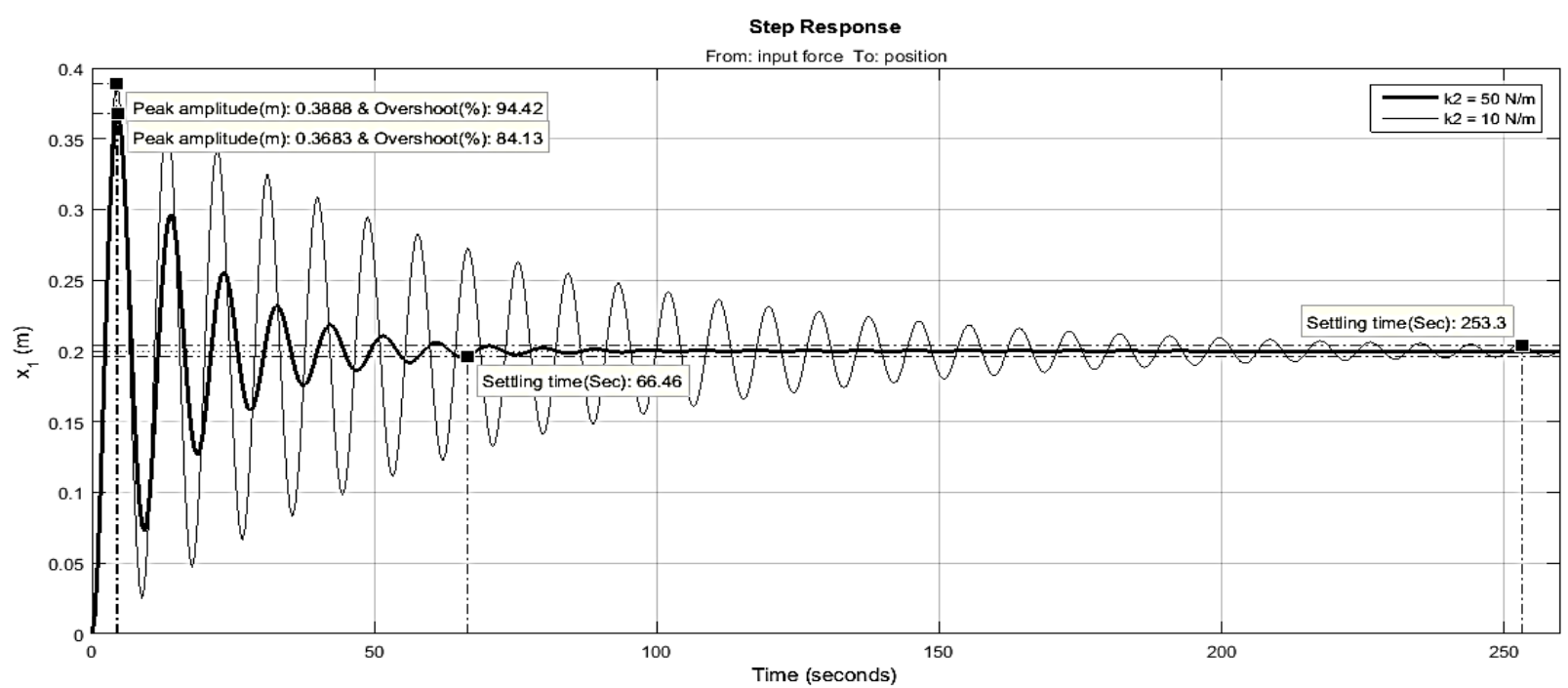

Figure 9: Effect of changing (k2) on the system 


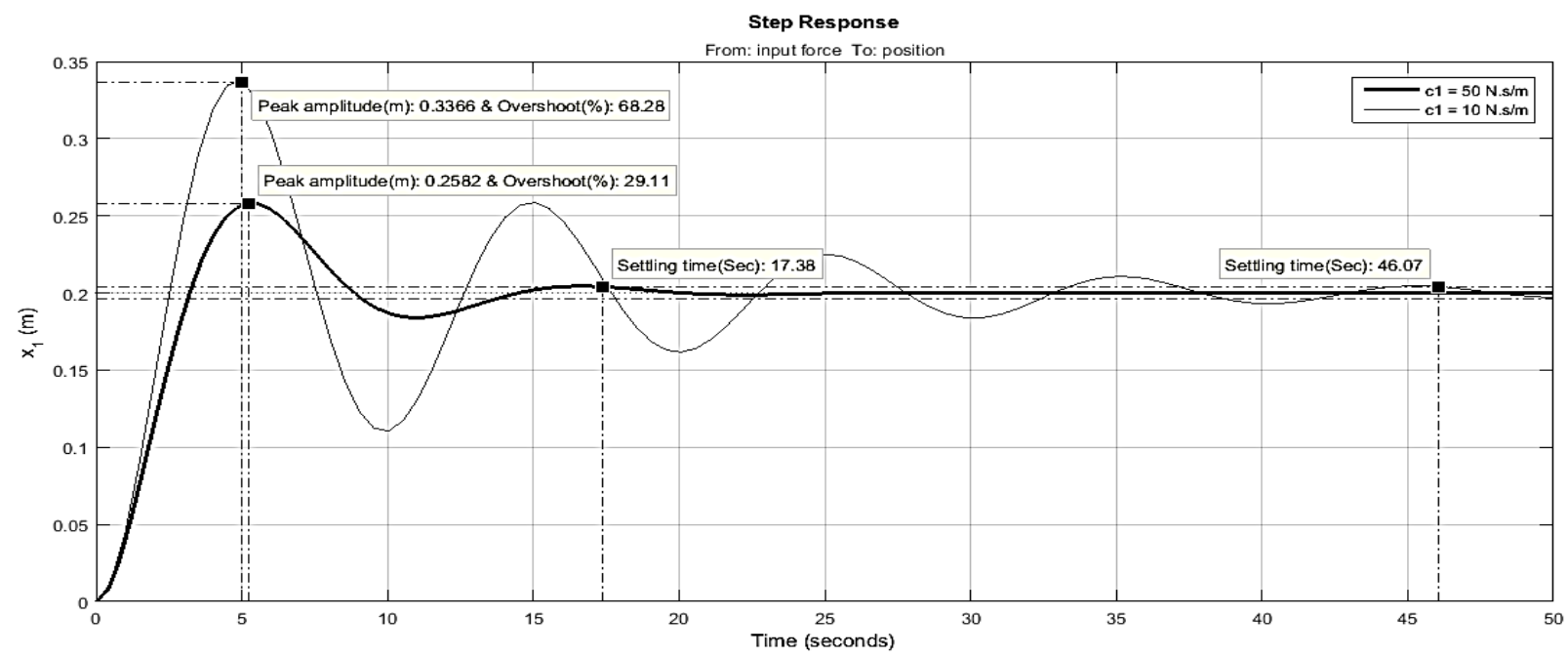

Figure 10: Effect of changing $\left(\mathrm{c}_{1}\right)$ on the system

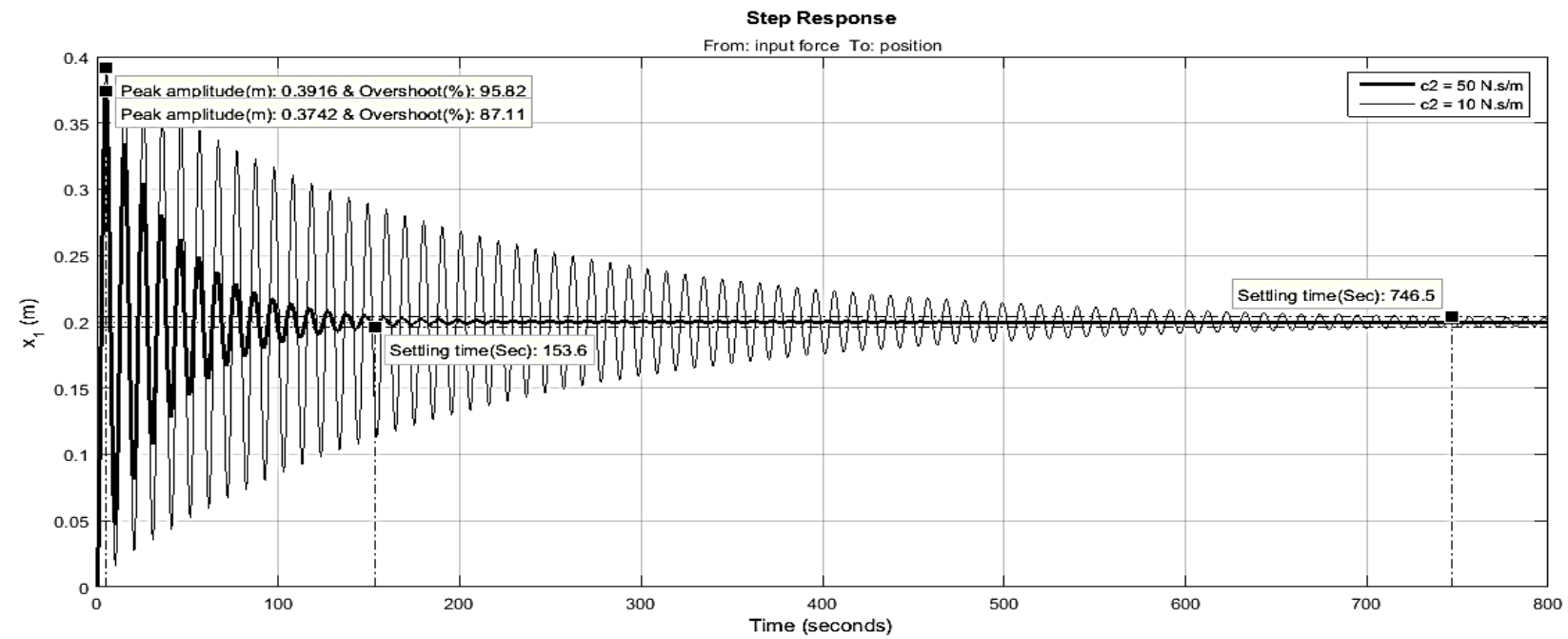

Figure 11: Effect of changing (c2) on the system

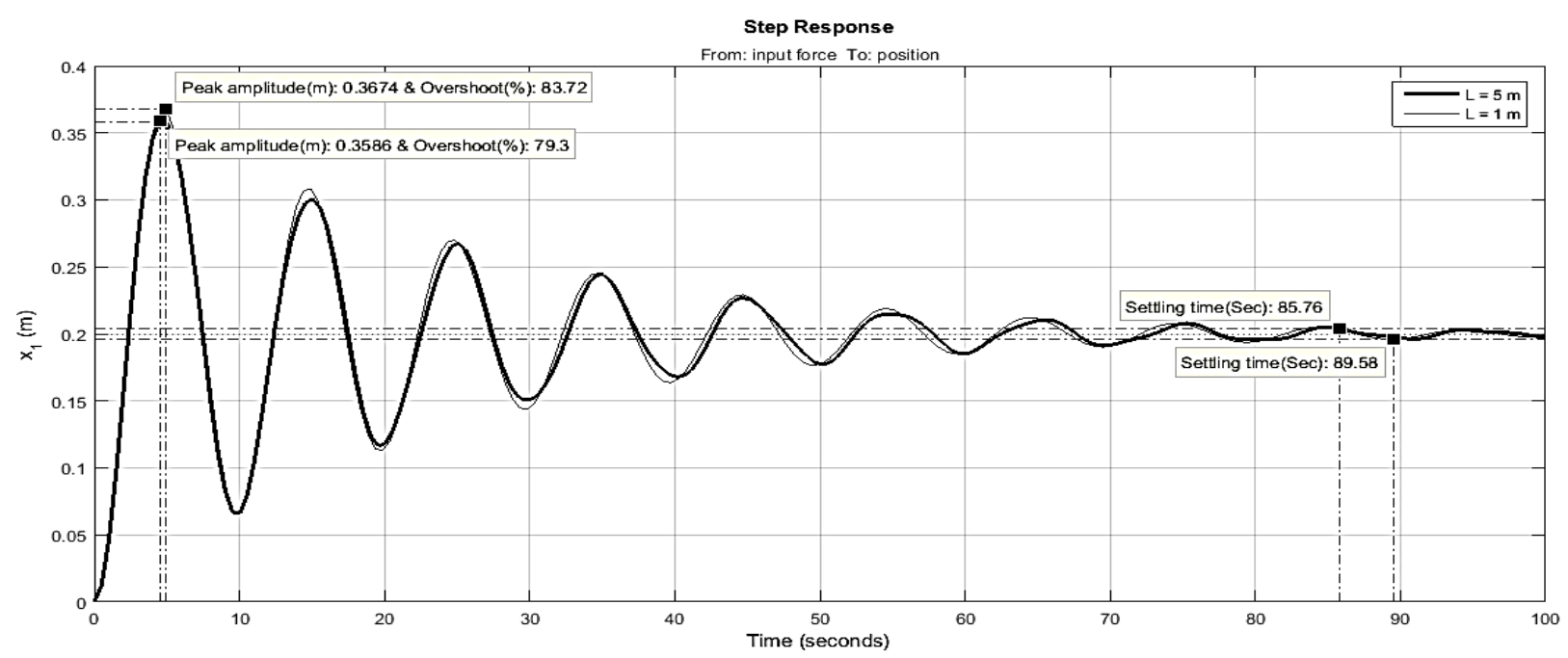

Figure 12: Effect of changing (L) on the system 


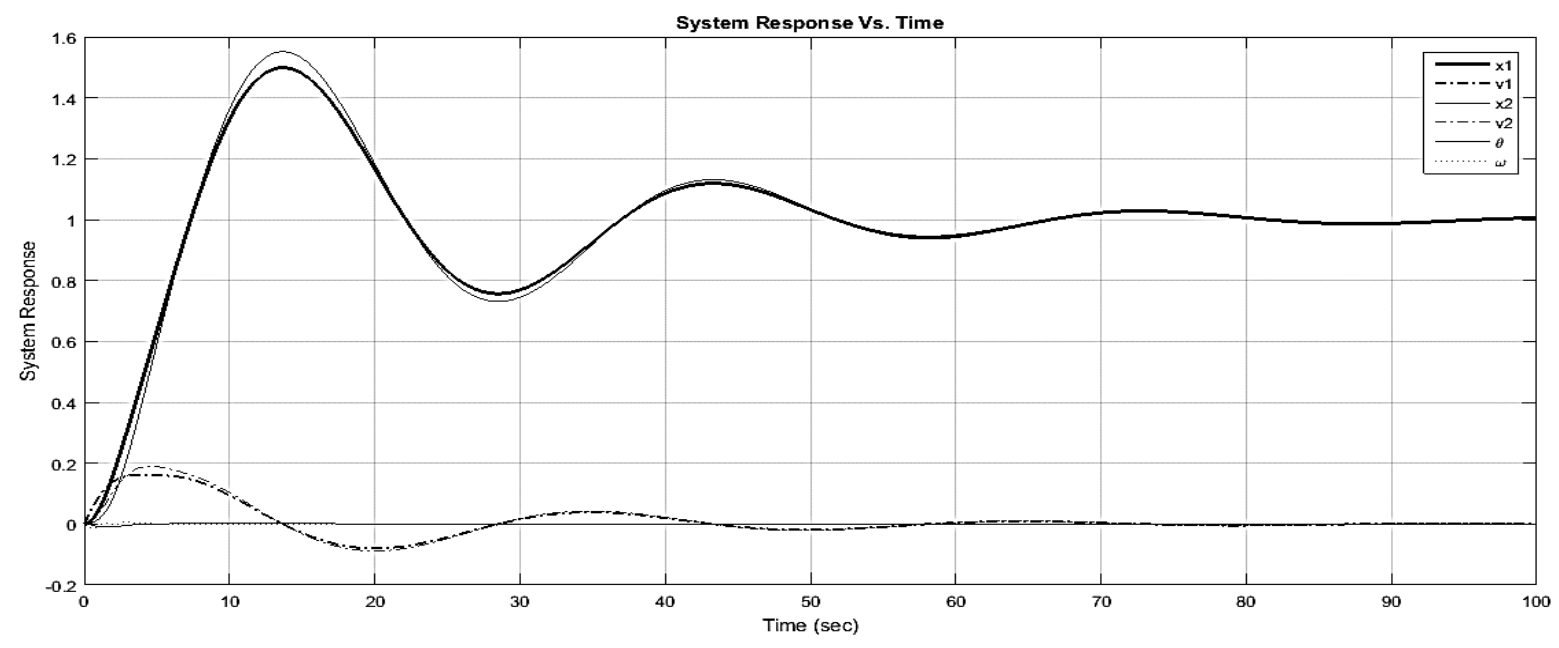

Figure 13: System Response Vs. Time

where, $\mathrm{v}_{1}$ : Linear velocity of the first mass $(\mathrm{m} / \mathrm{s})$

$\mathrm{V}_{2}$ : Linear velocity of the second mass $(\mathrm{m} / \mathrm{s})$

$\omega$ : Angular velocity of the third mass ( $\mathrm{rad} / \mathrm{s}$ )

\section{Conclusions}

Modelling and simulation of a structure provided with CPTMD are carried out in this paper. Lagrange's equation is used to develop the modelling equations. Moreover, the structure is excited by a constant force which is modelled by a step input function. In addition, an evaluation of the structure performance has been done, by considering the first peak amplitude as well as the settling time. Furthermore, the structure ability to damp out the oscillation increased dramatically as a result of increasing CPTMD components $\mathrm{m}_{2}, \mathrm{~m}_{3}, \mathrm{k}_{2}$, and $\mathrm{c}_{2}$. However, changing the pendulum link length $\mathrm{L}$ has an approximately negligible effect on the system. It is noticeable that the modelled structure has shown to be significantly affected by any change in its components $\mathrm{k}_{1}$ and $\mathrm{c}_{1}$. To summarize, simulation result has shown that the proposed CPTMD proved to be effective in attenuating the structure vibration besides reducing its amplitude. Also to restore the main system to its steady state much faster than before attaching the CPTMD to the structure.

\section{References}

[1] ASAD, S., SALAHAT, M., ZALATA, M.A., ALIA, M., and RAWASHDEH, A.A., 2011. Design of Fuzzy PD-Controlled Overhead Crane System with AntiSwing Compensation. Engineering 03, 07, 755762. DOI= http://dx.doi.org/10.4236/eng.2011.37091.

[2] BRZESKI, P., PAVLOVSKAIA, E., KAPITANIAK, T., and PERLIKOWSKI, P., 2015. The application of inerter in tuned mass absorber. International Journal of Non-Linear Mechanics 70, 20-29. DOI= http://dx.doi.org/10.1016/j.ijnonlinmec.2014.10. 013.
[3] CASCIATI, F. and GIULIANO, F., 2009. Performance of Multi-TMD in the Towers of Suspension Bridges. Journal of Vibration and Control 15, 6, 821-847. DOI= http://dx.doi.org/10.1177/1077546308091455.

[4] CHEN, K.-C., WANG, J.-H., HUANG, B.-S., LIU, C.-C., and HUANG, W.-G., 2013. Vibrations of the TAIPEI 101 skyscraper caused by the 2011 Tohoku earthquake, Japan. Earth, Planets and Space 64, 12, 1277-1286. DOI= http://dx.doi.org/10.5047/eps.2012.04.004.

[5] ELIAS, S., MATSAGAR, V., and DATTA, T.K., 2017. Distributed Multiple Tuned Mass Dampers for Wind Response Control of Chimney with Flexible Foundation. Procedia Engineering 199(2017/01/01/), 1641-1646. DOI= http://dx.doi.org/https://doi.org/10.1016/j.proe ng.2017.09.087.

[6] GUTIERREZ SOTO, M. and ADELI, H., 2013. Tuned Mass Dampers. Archives of Computational Methods in Engineering 20, 4, 419-431. DOI= http://dx.doi.org/10.1007/s11831-013-9091-7.

[7] HOUSNER, G.W., BERGMAN, L.A., CAUGHEY, T.K., CHASSIAKOS, A.G., CLAUS, R.O., MASRI, S.F., SKELTON, R.E., SOONG, T.T., SPENCER, B.F., and YAO, J.T.P., 1997. Structural Control: Past, Present, and Future. Journal of Engineering Mechanics 123, 9, 897-971. DOI= http://dx.doi.org/doi:10.1061/(ASCE)07339399(1997)123:9(897).

[8] K., D., S., M., L., M., and S., B., 2015. Case study of tuned mass damper and modeling of gyroscopic damper for corresponding effect. International Journal of Applied Research 1, 9, 219-221.

[9] KWOK, K.C.S., HITCHCOCK, P.A., and BURTON, M.D., 2009. Perception of vibration and occupant comfort in wind-excited tall buildings. Journal of Wind Engineering and Industrial Aerodynamics 
97, 7-8, 368-380. DOI= http://dx.doi.org/10.1016/j.jweia.2009.05.006.

[10] LI, C., 2002. Optimum multiple tuned mass dampers for structures under the ground acceleration based on DDMF and ADMF. Earthquake Engineering \& Structural Dynamics 31, 4, 897-919. DOI= http://dx.doi.org/10.1002/eqe.128.

[11] LUO, Y., SUN, H., WANG, X., ZUO, L., and CHEN, N., 2017. Wind Induced Vibration Control and Energy Harvesting of Electromagnetic Resonant Shunt Tuned Mass-Damper-Inerter for Building Structures. Shock and Vibration 2017, 1-13. DOI= http://dx.doi.org/10.1155/2017/4180134.

[12] MI HAN, S. and BENAROYA, H., 2002. Nonlinear and Stochastic Dynamics of Compliant Offshore Structures. Springer Netherlands.

[13] MOUSTAFA, K.A.F., TRABIA, M.B., and ISMAIL, M.I.S., 2009. Modelling and control of an overhead crane with a variable length flexible cable. Int. J. Comput. Appl. Technol. 34, 3, 216228.

$\mathrm{DOI}=$ http://dx.doi.org/10.1504/ijcat.2009.023945.

[14] NAGASE, T., 2000. Earthquake records observed in tall buildings with tuned pendulum mass damper. In Proceedings from the 12th world conference on earthquake engineering, Auckland, New Zealand.

[15] PEI, Y., LIU, Y., and ZUO, L., 2017. Regenerative Base Isolation With Multi-Resonant Electromagnetic Shunt Dampers, 58295, V003T032A001. DOI= http://dx.doi.org/10.1115/DSCC2017-5111.

[16] PEI, Y. and ZUO, L., 2017. Multi-Resonant Electromagnetic Shunt Dampers for Vibration Suppression, 58226, V008T012A061. DOI= http://dx.doi.org/10.1115/DETC2017-67559.

[17] QIAN, D., TONG, S., and LEE, S., 2016. FuzzyLogic-based control of payloads subjected to double-pendulum motion in overhead cranes. Automation in Construction 65, 133-143. DOI=http://dx.doi.org/10.1016/j.autcon.2015.12 .014 .
[18] ROFFEL, A.J. and NARASIMHAN, S., 2014. Extended Kalman filter for modal identification of structures equipped with a pendulum tuned mass damper. Journal of Sound and Vibration 333, 23, 6038-6056.

DOI= http://dx.doi.org/10.1016/j.jsv.2014.06.030.

[19] ROFFEL, A.J. and NARASIMHAN, S., 2016. Results from a Full-Scale Study on the Condition Assessment of Pendulum Tuned Mass Dampers. Journal of Structural Engineering 142, 1, 04015096. $\mathrm{DOI}=$ http://dx.doi.org/10.1061/(asce)st.1943541x.0001339.

[20] ROFFEL, A.J., NARASIMHAN, S., and HASKETT, T., 2013. Performance of Pendulum Tuned Mass Dampers in Reducing the Responses of Flexible Structures. Journal of Structural Engineering 139, 12, $04013019 . \quad$ DOI= http://dx.doi.org/doi:10.1061/(ASCE)ST.1943541X.0000797.

[21] SHI, W., WANG, L., LU, Z., and GAO, H., 2018. Study on Adaptive-Passive and Semi-Active Eddy Current Tuned Mass Damper with Variable Damping. Sustainability 10,2 , 99. DOI= http://dx.doi.org/10.3390/su10010099.

[22] SOONG, T.T. and SPENCER, B.F., 2002. Supplemental energy dissipation: state-of-the-art and state-of-the-practice. Engineering Structures $24, \quad 3 \quad(2002 / 03 / 01 /), \quad 243-259 . \quad$ DOI= http://dx.doi.org/https://doi.org/10.1016/S014 1-0296(01)00092-X.

[23] VERCAMBRE, T. and LOCCUFIER, M.P., 2017. Pendulum vibration absorbers for structural vibration control.

[24] ZUO, L., SUN, H., LUO, Y., and WANG, X., 2017. Seismic control of a SDOF structure through electromagnetic resonant shunt tuned massdamper-inerter and the exact $\mathrm{H} 2$ optimal solutions. Journal of Vibroengineering 19, 3, 2063-2079. DOI= http://dx.doi.org/10.21595/jve.2017.18256. 